\title{
O PROFESSOR FORMADOR E SUAS CRENÇAS DIDÁTICO-PEDAGÓGICAS
}

\section{TEACHER'S INITIAL TRAINING AND HIS EDUCATIONAL BELIEFS}

\author{
Letícia Ribeiro Lyra (leticia.lyra@uffs.edu.br) \\ Universidade Federal da Fronteira Sul - UFFS \\ José Francisco Custódio (j.custodio@ufsc.br) \\ Universidade Federal de Santa Catarina - UFSC
}

\begin{abstract}
Resumo: As crenças didático-pedagógicas incluem ideias sobre o que é ensinar, ser professor, avaliar, entre outras. O professor atua de acordo essas crenças sem ter, muitas vezes, suficiente reflexão da sua influência na prática docente. Frente a isso, partimos do pressuposto que as crenças didático-pedagógicas dos professores formadores possam influenciar a formação dos licenciandos quanto ao entendimento de como se ensina e aprende o conhecimento científico. Diante do exposto, realizamos uma pesquisa qualitativa com o objetivo de investigar as crenças didático-pedagógicas de professores formadores que atuam em cursos de Licenciatura em Ciências da Natureza e Matemática em uma universidade federal multicampi. Entrevistamos 16 professores formadores. Utilizamos a análise de conteúdo com construção de categorias $a$ posteriori. Em linhas gerais, os resultados apontaram que a maioria dos professores formadores, independente da área de formação, apresenta tendência a crenças didáticopedagógicas de caráter construtivista. Esperamos que esse artigo contribua com estudos futuros acerca da influência das crenças didático-pedagógicas dos professores formadores na formação inicial de licenciandos de Ciências da Natureza e Matemática.
\end{abstract}

Palavras-chave: Formação de Professores; Crenças de Ensino-Aprendizagem; Educação em Ciências e Matemática.

Abstract: The didactic-pedagogical beliefs include ideas about what it is to teach, to be
a teacher, to evaluate, among others. The teacher acts on these beliefs without often
having sufficient reflection on their influence on teaching practice. Given this, we
assume that the didactic-pedagogical beliefs of teacher educators can influence the
formation of undergraduates as to the understanding of how to teach and learn scientific
knowledge. Given the above, we conducted a qualitative research in order to identify
which didactic-pedagogical beliefs of teacher trainers who work in Bachelor of Science
in Nature and Mathematics at a federal university multicampi. We interviewed 16
teacher trainers. We use content analysis with a posteriori category building. In general,
the results pointed out that most teacher educators, regardless of the area of formation,
tend to constructivist didactic-pedagogical beliefs. We hope that this study will 
contribute to discussions about the initial formation of undergraduate students of Natural Sciences and Mathematics.

Keywords: $\quad$ Teachers $\quad$ training; $\quad$ Teaching-learning Beliefs; Education in Science and Mathematics.

\section{INTRODUÇÃO}

Os conhecimentos advindos das Ciências e Matemática fazem parte da vivência de todas as pessoas e são decisivos em nossa vivência como cidadãos (CURY; MARTINS; PINENT, 2012). De acordo com esses autores, as "crenças sobre essas áreas de conhecimento (ou sobre seus conceitos) determinam sua postura face ao mundo, que pode ser de submissão e aceitação ou de crítica e emancipação" (p.75).

Nesse sentido, consideramos que a alfabetização científica e tecnológica tem um papel muito importantResumo: Nos últimos anos houve um aumento no número de publicações científicas, nacionais e na formação cidadã dos estudantes da Educação Básica (CACHAPUZ et al., 2011, LEDERMAN; LEDERMAN; ANTINK, 2013; NÚÑEZ; RAMALHO, 2017; CHASSOT, 2018). No entanto, para que essa seja crítica e emancipatória, avaliamos ser necessário rever as visões distorcidas de Ciência que os professores de Ciências da Natureza e Matemática difundiram entre seus estudantes (PRAIA; CACHAPUZ,1994; GIL PÉREZ et al., 2001; CACHAPUZ et al., 2011).

De acordo com Cachapuz et al. (2011) são sete as visões deformadas de Ciência: 1) visão descontextualizada ou maniqueísta de Ciência neutra; 2) a visão de gênios isolados, que utilizam a experimentação e a observação neutra para 'descoberta' científica'; 3) utilização de modelo empírico-indutivista; 4) visão rígida, algorítmica e infalível da Ciência; 5) visão aproblemática e ahistórica, que não leva em conta as controvérsias científicas; 6) visão acumulativa e crescimento linear da Ciência.

Segundo esses autores, para modificar essa visão distorcida dos professores temos que considerar a importância das discussões sobre Ciência na sua formação inicial. Além disso, levar em conta quem foram seus formadores, considerando que, "o que os docentes pensam sobre ensinar e aprender está relacionado às suas experiências e à sua formação profissional, que exige que pensemos quem ensina e quem aprende no processo de formação" (BOLZAN; ISAIA, 2006, p. 494). 
Nesse sentido, partimos do pressuposto que os professores formadores apresentam crenças acerca do ensino e aprendizagem da Ciência que influenciarão na formação inicial dos futuros professores de Ciências da Natureza e Matemática da Educação Básica. Entendemos que os professores formadores são "todos os profissionais envolvidos nos processos formativos de aprendizagem da docência de futuros professores ou daqueles que já estão desenvolvendo atividades docentes" (MIZUKAMI, 2006, p.3).

Consideramos que apesar de nem sempre esses profissionais estarem conscientes de suas crenças, estas exerçam influência na formação dos licenciandos sobre como se ensina e aprende Ciência, consequentemente, sobre a ação docente desses como futuros profisssionais da Educação Básica. Diante disso, compreendemos que apesar de não ser o único mediador na formação inicial, concebemos que o professor formador será o principal “partícipe do processo de subjetivação dos docentes" (BATISTA, 2008, p. 5).

Segundo Borsato e Bzuneck (1999), os objetivos de educação partilhados pelo corpo docente de um curso de licenciatura podem moldar crenças dos futuros professores sobre ensinar e sua crença acerca do próprio papel de professor, por esse motivo, é importante compreender essas crenças na formação inicial.

Nessa linha de pensamento, Rego (2010) aponta que apenas haverá alteração na atuação dos professores da Educação Básica com relação a seus estudantes quando os profissionais que atuam com formação inicial modificarem suas práticas docentes. Para que isso aconteça, compreendemos que o professor formador necessita identificar quais crenças didático-pedagógicas traz em sua ação docente e que estejam repercutindo na formação dos futuros professores, para que possam revê-las, caso entendam que estejam sendo contraditórias com o que almejam para a formação inicial.

Nesse viés, entendemos que investigar as crenças didático-pedagógicas de como se ensina e aprende Ciência entre professores formadores pode possibilitar o fomento de políticas de formação inicial de licenciandos para a Educação Básica de maneira diferenciada. Pois, concordamos como Pajares (1992), que aponta que compreender as crenças é essencial para melhorar as práticas de formação e de ensino e, consequentemente, a atuação dos futuros professores desse nível educacional. 
Diante do exposto, realizamos uma pesquisa qualitativa com o objetivo de investigar as crenças didático-pedagógicas de professores formadores que atuam em cursos de Licenciatura em Ciências da Natureza e Matemática em uma universidade federal multicampi.

\section{CRENÇAS DIDÁTICO-PEDAGÓGICAS E ATUAÇÃO DOCENTE: APONTAMENTOS}

Desde que nascemos, vamos aprendendo a olhar o mundo por meio de filtros, as crenças. Essas têm recebido uma grande atenção por parte dos investigadores educacionais e sido amplamente discutidas na literatura (FUNDA SAVASCIACIKALIN, 2009). As crenças são uma das formas de pensamento humano e inseremse na linha investigativa sobre o pensamento do professor proposta na década de 1970 (SADALLA, 1998; BRAZ, 2007).

Segundo Pajares (1992), as crenças vão se construindo e se modificando ao longo da nossa vida pelas nossas interações familiares, sociais e educacionais e se transformam em um saber pessoal que orienta e interfere em nosso comportamento e na tomada de decisões diárias. Para esse autor, essas não são conscientes e estão vinculadas a aspectos afetivos e valorativos. É importante destacarmos que essas vão-se solidificando sem reflexão. Segundo Bzuneck e Borsato (1999, p. 5), “com o tempo, tais crenças vão se depurando, consolidando-se, entrelaçando-se, formando redes".

Para Rokeach (1981), há um sistema de crenças que representa universo total de crenças de uma pessoa. Uma parte desse sistema é composta pelas crenças educacionais (PAJARES, 1992). Definimos que as crenças educacionais são elaborações internas, portanto individuais, sobre como os professores concebem os processos de ensinar e aprender os conteúdos científicos.

Portanto, condicionam o processo de decisão didático-pedagógica dos professores, influenciando antes, durante e após sua atuação docente (RAMÍREZ, 2005). Porém, muitas vezes, o professor atua de acordo com suas crenças sem ter, muitas vezes, suficiente reflexão da influência dessas sobre sua prática (PAJARES, 1992; MIZUKAMI, 2006). 
Considerando-se que há uma pluralidade de crenças educacionais que possam exercer influência sobre a prática do professor, definimos por destacar as crenças didático-pedagógicas. Essas se referem às crenças sobre ensino, currículo, avaliação, relação professor-aluno, dentre outras. São construídas desde a infância, pela observação ao longo dos anos que se passa na escola e já "estão bem estabelecidas no momento em que um aluno frequenta a faculdade" (PAJARES, 1992, p. 132, tradução livre).

Neste trabalho, os termos didático, pedagógico e didático-pedagógico serão utilizados como sinônimos. Pimenta (1999) aponta que esses termos têm sido tratados como distintos e desarticulados, uma vez que a didática estaria relacionada ao saber ensinar e o pedagógico estaria relacionado aos aspectos relacionais professor-aluno, sobre a aprendizagem, dentre outros. A autora sugere que essa dicotomia seja superada e que "a renovação da didática terá por base os aspectos pedagógicos" (PIMENTA, 1999, p. 25).

As crenças didático-pedagógicas são manifestadas na prática docente pelo modelo de ensino e aprendizagem que o professor formador adota. Considerando que podem ser várias denominações para esses modelos, em nossa investigação adotamos a terminologia: caráter tradicional e caráter construtivista (PALMA, 2009; CARVALHO; GIL-PÉREZ, 2011).

Os professores com crenças de caráter tradicional apresentam um modelo de ensino simplista da Ciência, como verdade absoluta e inquestionável, baseado na transmissão de conteúdo, no qual basta ao professor ter conhecimento da matéria a ser ensinada (CARVALHO; GIL-PÉREZ, 2011), a "qual deve ser entregue aos alunos numa versão simples e atualizada" (PALMA, 2009, p. 512).

O docente apresenta um modelo pedagógico diretivo: o professor é quem 'organiza' e 'transmite' o conhecimento e cabe ao aluno 'memorizá-lo' (BECKER, 2013). Acredita que todo conhecimento provém da experiência, que está fora do sujeito, por exemplo, no professor (autoridade onisciente) e nos livros (SCHOMMER-AIKINS, 2004).

Não levam em conta o conhecimento prévio dos alunos e sua metodologia deve ser planejada e seguir uma sequência lógica, visando a repetição e memorização de 
algoritmos, conceitos, fórmulas, etc. Acreditam que a avaliação é para comprovar o nível de conhecimento dos alunos, ocorrendo, preferencialmente, por meio de provas escritas (PALMA, 2009) e que os estudantes não podem participar da elaboração dos critérios avaliativos.

Nessa perspectiva, o professor deve seguir o currículo prescrito. Esses profissionais pautam-se por uma postura epistemológica empirista-indutivista e positivista e orientam a apresentação de um currículo enciclopédico, cientificista, conteudista, voltado à memorização e ao acúmulo de informações (LOPES, 2007).

Os professores com crenças de caráter construtivista apresentam uma visão de Ensino de Ciências e Matemática que evidencia conteúdos historicamente contextualizados, provisórios e sujeitos à contestação (MORAES, 2000; BECKER, 2013). Esses professores baseiam-se numa atitude epistemológica interacionista (BECKER, 2013), na qual há valorização do conteúdo, ao mesmo passo que esses não são vistos como prontos e acabados, sendo continuamente revistos e construídos (MORAES, 2000).

Nessa perspectiva, considera-se que o estudante tem conhecimentos prévios e deve ser considerado seu contexto sociocultural, para que esse (re) construa o conhecimentohistacmente construído (CACHAPUZ et al., 2011; BECKER, 2013; PALMA, 2009).

A atuação desse professor baseia-se num modelo de pedagogia relacional em que, entendem que o professor, a partir da atividade e da problematização da sua ação, auxilia o estudante a construir seu conhecimento (BECKER, 2013; MORAES, 2000; PALMA, 2009). Para esses professores, a metodologia deve ser mais variada e levar em conta a motivação e participação dos alunos.

Entendem que a prova escrita não é o único meio de avaliação e que os estudantes podem participar na elaboração dos critérios avaliativos (PALMA, 2009). Avaliam que o contexto sociocultural deve ser considerado para que o aluno construa seu conhecimento (PALMA, 2009). Apresentam flexibilidade para incorporar conteúdos além dos estabelecidos pelo currículo oficial (DELIZOICOV et al., 2011).

O exame sobre modelo de ensino possibilita inferir que se o docente formador tiver crenças de caráter mais construtivista, aumentará a probabilidade de evitar tratar a 
Ciência como sendo 'neutra', construída por 'gênios', a-histórica e acrítica, baseado no modelo empirista-indutivista e positivista ainda presente na Educação Científica e Tecnológica (CACHAPUZ et al., 2011; HARRES, 1999).

Ponderamos que o termo construtivismo é obscuro e confuso, pois apresenta diferentes vertentes teórico-epistemológicas (CUSTÓDIO et al., 2013). Em um estudo aprofundado sobre o Construtivismo, Chakur (2015) desconstrói as crenças equivocadas sobre essa teoria entre professores, críticos e autores construtivistas. Segundo a autora, há "distorções nas tentativas de transposição do Construtivismo para o campo da Educação" (CHAKUR, 2015, p. 154), que mascaram a teoria Epistemológica e Psicológica proposta por Piaget.

Em síntese, entendemos que os professores formadores têm crenças didáticopedagógicas de caráter tradicional ou de caráter construtivista e que essas tenham influência na formação inicial dos futuros professores de Ciências da Natureza e Matemática.

\section{PERCURSO METODOLÓGICO}

A fim de investigarmos as crenças didático-pedagógicas dos professores formadores dos cursos de licenciatura em Ciências da Natureza e Matemática da universidade federal, onde desenvolvemos a pesquisa, realizamos entrevistas semiestruturadas.

A instituição de ensino superior em tela oferta sete cursos de licenciatura nas áreas de Ciências e Matemática em três diferentes campi. Os professores formadores convidados para a entrevista foram aqueles que atuavam em componentes curriculares que tratavam de conhecimentos específicos/disciplinares. Concordamos com Fiorentini (2005) que esses docentes são os que mais influenciam a formação pedagógica do futuro professor:

[...] as disciplinas específicas influenciam mais a prática do futuro professor do que as didático-pedagógicas, sobretudo porque as primeiras geralmente reforçam procedimentos internalizados durante o processo anterior de escolarização e as prescrições e recomendações das segundas têm pouca influência sobre em suas práticas posteriores (FIORENTINI, 2005, p. 111). 
A opção pela entrevista está relacionada ao fato de as crenças poderem se manifestar por meio de declaração verbal e escrita (PALMA, 2009). Bardin (2016, p.94) destaca que "uma entrevista é, muitas vezes, polifônica". Nesse caso, a entrevista configurou-se como um instrumento mais adequado para obter informações das crenças didático-pedagógicas dos professores formadores com diferentes formações.

A escolha pela modalidade semiestruturada deveu-se a ser que "frequentemente elas dizem respeito a uma avaliação de crença, sentimentos, valores, atitudes, razões e motivos" (ROMANELLI; BIASOLI-ALVES, 1998, p. 145). Entrevistamos ${ }^{1}$, ao todo, 16 professores formadores dos cursos de Licenciatura em Ciências da Natureza e Matemática de três Campi da universidade em tela, entre os meses de janeiro e março de 2018.

Quanto ao perfil dos respondentes temos que cinco são professores formadores de Biologia, quatro de Física e de Matemática e três de Química, com idade de 30-39 anos (sete). A maioria dos respondentes são mulheres (nove).

A maioria dos respondentes é licenciado (12), têm doutorado (14), sendo a maior parte em áreas de conhecimento específico (11). Destacamos que todos os respondentes da área de Química são doutores em Educação em Ciências, um professor formador de Física é doutor em Educação e um professor formador de Matemática é doutor em Educação Matemática. Desses docentes, dois são pós-doutores, sendo um em Educação Científica e Tecnológica e outro em Física.

Consideramos esses dados significativos, pois sinalizam que esses professores formadores apresentam formação didático-pedagógica para atuarem nas licenciaturas, o que contraria que "apenas uma parte do corpo docente envolvido com cursos de formação de professores tem algum tipo de preparação pedagógica" (MIZUKAMI, 2006, p. 1).

Destacamos que a maioria dos respondentes (12) tem entre 7-25 anos de atuação como docentes, o que Huberman (1995) destaca como uma fase em que os professores apresentam ativismo profissional (lançam-se novas formas de avaliação, metodologias, entre outros) ou de questionamento de si, quando a sensação de rotina ou crise

1 Entrevista aprovada pelo Comitê de Ética com Seres Humanos, CAAE: 79464617.7.0000.5564. 
existencial fica mais evidente, especialmente quando o professor faz um balanço da vida profissional e a avalia como tendo mais perdas do que ganhos profissionais.

Para a elaboração das análises dos dados, optamos pela abordagem qualitativa, pois, concordamos com Pajares (1992), que aponta que essa é relevante e adequada para análise das crenças educacionais.

Utilizamos a análise de conteúdo proposta por Bardin (2016), com construção de categorias a posteriori. Para tal, realizamos uma pré-análise, seguida de codificação do material e, por fim, a categorização. A pré-análise consistiu na organização propriamente dita das respostas das entrevistas e a leitura flutuante e exaustiva dessas. Para a organziação das respostas, transcrevemos separadamente cada questão com todas as declarações dos professores formadores, a fim de termos uma panorama das falas.

Após essa etapa, fizemos a exploração do material e a codificação, que é a transformação do material, na qual selecionamos todas as falas que reportassem às crenças didático-pedagógicas investigadas. Em seguida, realizamos a categorização do material, com categorias a posteriore.

As categorias que emergiram das falas dos professores foram: o ensino da Ciência e da linguagem científica, o bom professor, a avaliação, a Didática das Ciências e Matemática e o planejamento didático-pedagógico. Dessas categorias criamos duas subcategorias: uma que retratava o modelo de ensino simplista de Ciências, baseado na transmissão de conteúdo, no qual basta ao professor ter conhecimento da matéria a ser ensinada (CARVALHO; GIL-PÉREZ, 2011), em que denominados de crenças de caráter tradicional; e outra, envolve uma (re) construção do conhecimento científico por parte dos estudantes (CACHAPUZ et al., 2011), em que nomeamos de crenças de caráter construtivista.

A fim de garantir a privacidade dos respondentes, todos os professores formadores foram denominados de $\mathrm{P}$, seguido de uma letra que representa a área de formação e um número, que representa o tempo de atuação. Por exemplo: $\left(\mathrm{PB}_{6}\right)$ é um professor formador de Biologia, que atua há seis anos como docente, seja na Educação Básica e/ou na Educação Superior. 
Passaremos às análises das crenças didático-pedagógicas dos professores formadores.

\section{O QUE PENSAM OS PROFESSORES FORMADORES?}

Nessa seção apresentaremos os resultados referentes às análises das entrevistas realizadas com 16 professores formadores que atuam com componentes curriculares específicos. Destacamos que as análises das falas foram realizadas levando em consideração a área de atuação docente e não como falas personalizadas. Dessa forma, apresentaremos as verbalizações dos professores formadores, selecionadas em função de categorias e subcategorias de análise.

Em nosso artigo, selecionamos um exemplar de fala por categoria, considerando que representam ideias expressas pela maioria dos professores formadores entrevistados.

Quanto às crenças sobre Ensino da Ciência, selecionamos a seguinte fala:

é entrar nesse novo universo que é o universo específico da Química para que ela tenha mais oportunidade de se posicionar na vida [...] é o grande desafio fazer com que o aluno compreenda que você [professor] está tentando mediar com ele $\left(\mathrm{PQ}_{12}\right.$, grifos nossos).

Identificamos nessa fala e na maioria dos professores formadores entrevistados $(11)^{2}$, que esses apontam para uma tendência de ensino com traços mais construtivistas, uma vez que destacam a importância do ensino da Ciência para formação cidadã do estudante e com mediação do professor (CACHAPUZ et al., 2011; NÚNEZ; RAMALHO, 2017).

Quanto às crenças sobre Linguagem Científica, destacamos a fala:

acho importante, ele tem que dominar essa linguagem [...] que ele consiga falar entre os pares e aquela linguagem que ele consegue levar para o leigo para o aluno lá do fundamental ou com as crianças dos iniciais. ( $\mathrm{PB}_{18}$, grifos nossos).

Em geral, identificamos nessa fala e em outras que a maioria dos professores formadores (11), independente da área de atuação, trata da questão da linguagem

\footnotetext{
${ }^{2}$ Esse número correponde às falas por categorias. Utilizaremos esse critério ao longo da análise.
} 
científica considerando-a muito importante para uma boa docência futura, bem como para interlocução com pares e leigos, o que auxiliaria na divulgação científica. Segundo Vigotski (2000), o pensamento se dá na e pela linguagem. Daí a importância dos estudantes se apropriarem da linguagem científica, pois ampliarão e modificarão seu pensamento para níveis mais abstratos e generalizados.

De nossa parte, entendemos que a apropriação da linguagem científica seja fundamental para a Alfabetização Científica e Tecnológica. Chassot (2018) discute o poder da linguagem científica em seu papel (trans)formador ou reprodutor de visões estereotipadas da Ciência.

Quanto à crença do Bom Professor, selecionamos a seguinte fala:

é o que promove uma reflexão [...] eu tenho que mostrar para eles essas relações que estão aí ( $\mathrm{PM}_{31}$, grifos nossos).

Essa fala é representativa da maioria dos professores formadores (13), pois externaliza que o bom professor é o que permite ao aluno pensar, refletir, o que poderíamos entender como uma atuação mais construtivista. Também identificamos que muitos apontam que ter características pessoais (humildade, responsabilidade, etc.), associadas a ações didáticas são fundamentais para se definir um bom professor.

Identificamos que os professores formadores destacam o conhecimento como uma necessidade para o bom professor. Ressaltam também a importância do professor em saber 'ensinar', o que pode ser entendido como o conhecimento didático sobre o conteúdo (SHULMAN, 2014) associado a características pessoais do professor, tais como afetividade, empatia etc. Para esse autor, todas as características são importantes, mas o conhecimento pedagógico do conteúdo é a principal característica da formação e que melhor distingue um especialista de um pedagogo, uma vez que o professor transforma conhecimento de conteúdo em formas de ensino.

Esse autor destaca também que o professor tem que se atentar em relação ao conhecimento do conteúdo, pois a maneira como o comunica qualifica o que é essencial e periférico na disciplina, bem como influencia o entendimento do estudante acerca do que considera como uma 'verdade' naquela ciência (SHULMAN, 2014). Essa é a visão 
compartilhada também por Núñez e Ramalho (2017) quando destacam a importância do conhecimento disciplinar por parte do formador de professores.

Quanto à crença acerca da Avaliação da aprendizagem identificamos que a fala abaixo representa o entendimento da maioria dos entrevistados:

[uso] diferentes instrumentos [...] tenho usado desenhos [...] a reescrita de provas; então, eu faço a questão da avaliação individual [...] depois eu dialogo com eles no próximo encontro com que como que eles evoluíram ou não nessa escrita outra questão de avaliação são os próprios relatos; as leituras que eles realizam $\left(\mathrm{PQ}_{12}\right.$, grifos nossos).

Esses docentes parecem sinalizar o que Uhmann e Zanon (2016, p. 250) ressaltam sobre a avaliação:

o objetivo da avaliação não é aprovar ou reprovar, mas acompanhar o processo de construção do conhecimento. Através da prática pedagógica precisamos intervir para identificar as lacunas e os avanços, bem como ser capaz de identificar o inesperado, aquilo que não estava previsto a priori. São ações mediadas e interativas que podem proporcionar a construção do conhecimento pelo sujeito se ele deseja pensar/refletir sobre a sua própria formação.

Identificamos nas falas analisadas que a maioria dos professores formadores (11), independente da área de atuação, problematiza o processo de avaliação, preferindo utilizar diferentes estratégias para avaliar o conteúdo conceitual, o que concorda com o proposto por Carvalho e Gil-Pérez (2011), para quem é necessário superar o modelo avaliativo de memorização e considerá-lo como saberes necessários para a formação docente.

Nesse sentido, analisamos que a maioria dos professores formadores entrevistados coadunam com a proposta de uma avaliação formativa, com tendência mais de caráter construtivista.

Quanto à crença acerca da Didática das Ciências/Matemática temos a seguinte fala:

parto do pressuposto que para ensinar determinado conteúdo é preciso conhecer determinado conteúdo $[\ldots]$ eu ensino esses conteúdos e busco ensiná-los da maneira que os estudantes deveriam fazê-lo quando forem os primeiros interlocutores de Ciências e alguns indivíduos quando eles estiverem dando Física na Educação Básica porque esse é o primeiro contato que aqueles indivíduos tem com aquela Ciência ( $\mathrm{PF}_{8}$, grifos nossos). 
Identificamos que essa fala representa a maioria dos professores formadores (11) que consideram necessário o tratamento do conhecimento pedagógico do conteúdo em seus componentes curriculares, o que parece sugerir uma crença de caráter construtivista da formação docente.

No entanto, ainda identificamos, em algumas falas (5 professores formadores) tal como a afirmação abaixo, a presença da crença de caráter tradicional, marcada pela racionalidade técnica de ensino, na qual o conteúdo não é tratado em sua dimensão pedagógica:

\footnotetext{
Eu deixo bem claro, que o conteúdo que eu ensino é sempre mais profundo do que aquilo que eles vão ensinar lá eles têm que saber [...] eu não trabalho com modelagem com essas coisas eu deixo para eles fazerem lá na prática [citou PIBID, PET, etc.] ( $\mathrm{PB}_{20}$, grifos nossos).
}

Identificamos nessa fala e de outros professores formadores que esses levam em conta as discussões sobre ensino e aprendizagem das Ciências/Matemática importantes na formação de professores, não o fazem ou o fazem sem intencionalidade didática. Concordamos que o conhecimento disciplinar é fundamental (NÚÑEZ; RAMALHO, 2017), mas sempre associado ao conhecimento pedagógico do conteúdo (SHULMAN, 2014).

Em linhas gerais, muitos entendem que há uma didática específica para a Ciências/Matemática que deve ser levada em conta na formação inicial de professores, mas ao que parece ainda há uma visão de que simplista do ensino, que somente são necessários o domínio do conteúdo disciplinar, a prática pedagógica e conhecimentos didáticos usuais (CACHAPUZ et al., 2001).

Quanto à crença no planejamento didático-pedagógico, destacamos a seguinte fala:

uso muitas metodologias práticas, nessas que envolvem práticas, mas sempre discussão; eu discuto muito e eu trago sempre artigos ( $\mathrm{PB}_{7}$, grifos nossos).

Identificamos nessa fala e de outros professores formadores, que a maioria dos entrevistados (11) tende a planejar suas aulas com atividades didático-pedagógicas mais voltadas a construção do conhecimento pelo aluno. 
Em síntese, identificamos uma prevalência da tendência a crenças didáticopedagógicas de caráter construtivista entre os professores formadores. Esses resultados contestam o que Briceño e Benarroch (2012) e Briceño, Benarroch e Marín (2013) apontaram em seus estudos com professores universitários de Ciências. Eles concluíram que são mais abundantes as concepções empiristas em relação às construtivistas sobre a Ciência, há a prevalência das concepções reducionistas sobre o ensino e um relativo desconhecimento do processo de aprendizagem entre os docentes.

\section{REFLEXÕES FINAIS}

Em linhas gerais, os resultados apontaram que a maioria dos professores formadores entrevistados, independente da área de formação, apresenta tendência a crenças didático-pedagógicas mais voltadas ao construtivismo.

Quanto ao ensino da Ciência e da linguagem científica indicam uma perspectiva de Alfabetização Científica e Tecnológica cidadã, em que desmitificam crenças de neutralidade a sobre a Ciência e os cientistas e abordam "as terríveis desigualdades ocasiadas pelo uso inadequado da Ciência e Tecnologia e suas implicações sociopolíticas" (NÚÑEZ; RAMALHO, 2017, p.15).

Quanto ao bom professor, identificamos que a maioria dos respondentes apresenta uma visão construtivista, considerando o conhecimento pedagógico do conteúdo aliado às características pessoais (saber escutar, empatia, etc.) que levam em conta a interação com aluno.

Em relação à avaliação, constatamos que a maioria apresenta diversas expressões dessa, o que sugere indicar uma perspectiva mais construtivista sobre essa prática. Identificamos também que a maioria parece apresentar crença de caráter construtivista sobre a Didática das Ciências/Matemática, uma vez que buscam trabalhar $o$ conhecimento pedagógico do conteúdo.

Quanto ao planejamento didático-pedagógico, detectamos que a maioria dos respondentes trabalha com atividades didáticas interativas, o que parece indicar crenças construtivistas. 
Enfim, consideramos que esse artigo possa servir de referência para estudos futuros que tratem das implicações das crenças didático-pedagógicas de professores formadores na formação inicial de professores que atuarão com a Educação Científica e Tecnológica na Educação Básica.

\section{REFERÊNCIAS}

BARDIN, L. Análise de conteúdo. São Paulo: Ed.70, 2016.

BATISTA, S. H. Formação de professores e aprendizagem: tecendo encontros. Revista @ambienteeducacao. v. 1, n. 1, jan.-jul. 2008.

BECKER, F. Epistemologia do professor: o cotidiano da escola. 16 ed. Petrópolis, RJ: Vozes, 2013.

BOLZAN, D.; ISAIA, S. Aprendizagem docente na educação superior: construção e tessituras da profissionalidade. Educação, PUC, Porto Alegre, RS, ano XXIX, v.60, n.3, p.489-501, set- dez, 2006.

BORSATO, E.; BZUNECK, J. A. Crenças de futuros professores: sua Relação com as fases no curso e com a experiência de ensino. In: II Seminário de Pesquisa em Educação da Região Sul (Fórum Sul da ANPED), Curitiba, v. 1. 1999.

BRAZ, A. O pensamento do professor: pressupostos e dimensões de estudo. Contrapontos, v.7, n. 2, p. 365-380, Itajaí, mai - ago, 2007.

BRICEÑO, J. J.; BENARROCH, A. Concepciones y creencias sobre ciencia, aprendizaje y enseñanza de profesores universitarios de ciencias. REIEC, v. 8, n. 1, jun, p. 24-41, 2012.

BRICEÑO, J. J.; BENARROCH, A.; MARÍN, A. N. Coherencia Epistemológica entre ciencia, aprendizaje y enseñanza de profesores universitarios colombianos. Comparación de resultados con profesores chilenos y españoles. Enseñanza de las ciencias, n. 31.v. 2, p. 55-74, 2013.

BZUNECK, J. A.; BORSATO, E. Tendências Contemporâneas no Estudo de Crenças Educacionais de Professores e de Alunos de Licenciaturas. In: II Seminário de Pesquisa em Educação da Região Sul (Forum Sul da ANPED), Curitiba, v.1, 1999. CACHAPUZ, A.; GIL-PEREZ, D.; CARVALHO, A. M.; PRAIA, J. VILCHES, A. A necessária renovação do ensino das ciências. 2 ed., São Paulo, Cortez, 2011.

CARVALHO, A.M.; GIL-PÉREZ, D. Formação de professores de Ciências: tendências e inovações. 10. ed., São Paulo: Cortez, 2011 
CHAKUR, C. A desconstrução do construtivismo na Educação: crenças e equívocos de professores, autores e críticos. São Paulo: Editora UNESP, 2015.

CHASSOT, A. Alfabetização Científica: questões e desafios para a Educação. 8.ed. Ijuí: Ed. Ijuí, 2018.

CURY, H.; MARTINS, M.; PINENT, C. E. Crenças de alunos de Ensino Superior sobre Ciências e Matemática. Didasc@lia: Didáctica y Educación, v. 3, n.2, p.71-86, 2012.

CUSTÓDIO, J. F.; ALVES FILHO, J. P.; CLEMENT, L.; FERREIRA, G. Práticas didáticas construtivistas: critérios de análise e caracterização. TED, n.33, p. 11 - 35, enero - junio, 2013.

DELIZOICOV, D.; ANGOTTI, J.; PERNAMBUCO, M. Ensino de Ciências: fundamentos e métodos. 4. ed. São Paulo: Cortez, 2011.

FIORENTINI, D. A Formação Matemática e Didático-Pedagógica nas Disciplinas da Licenciatura em Matemática. Revista de Educação PUC, Campinas, SP, n.18, p.107115, jun. 2005.

FUNDA SAVASCI-ACIKALIN. Teacher beliefs and practice in science education.

Asia-Pacific Forum on Science Learning and Teaching, v.10, i.1, article 12, p. 1-12, jun., 2009.

GIL PÉREZ, D.; MONTORO, I. F; ALÍS, J.; PRAIA, J. Para uma imagem não deformada do trabalho científico. Ciência e Educação, v.7, n. 2, p.125-153, 2001.

HUBERMAN, M. O ciclo de vida profissional dos professores. In: NÓVOA, A. (org). Vidas de professores. 2. ed. Portugal: Porto Ed., 1995, p.31-62.

LEDERMAN, N.; LEDERMAN, J. S.; ANTINK, A. Nature of science and scientific inquiry as contexts for the learning of science and achievement of scientific literacy. International Journal of Education in Mathematics, Science and Technology, v.1, n.3, p.138-147, 2013.

LOPES, A. Currículo e Epistemologia. Ijuí: Editora UNIJUÍ, 2007.

MIZUKAMI, M. G. N. Aprendizagem da docência: professores formadores. Revista Ecurriculum, v. 1, n. 1, dez-jul, São Paulo, 2006.

MORAES, R. É possível ser construtivista no ensino de Ciências? In: MORAES, R. (Org.). Construtivismo e ensino de ciências: reflexões epistemológicas e metodológicas. Porto Alegre/RS: EDIPUCRS, 2000, p. 103-129.

NÚÑEZ, I.; RAMALHO, B. O conhecimento disciplinar docente para ensinar ciências naturais: reflexões sobre a formação inicial de professores. Revista Temas em Educação, João Pessoa, v.26, n. 2, p. 10-37, jul./dez. 2017.

PAJARES, F. Teachers` belifes and educational research: cleaning up a messy constructic. Review of Educational Research, v. 62, n.3, p.307-332, 1992. 
PALMA, S. Creencias curriculares y creencias de actuación curricular de los professores de ciencias chilenos. Revista Electrónica de Enseñanza de las Ciencias, v. 8, n. 2, p.505-526, 2009.

PIMENTA, S. Formação de professores: identidade e saberes da docência. In: PIMENTA, S. (org.) Saberes pedagógicos e atividade docente. São Paulo: Cortez, 1999, p.15-34.

PRAIA, J.; CACHAPUZ, F. Un analisis de las concepciones acerca del conocimento cientifico de los profesores portugueses de la enseñanza secundária. Revista Investigación y experiencias didácticas. v.12, n3, p.350-354, 1994.

RAMÍREZ, E. Concepciones curriculares del profesorado de Física y Quimica en formación inicial. Tese (doutorado) Universidade de Sevilla, Faculdad de Ciência de la Educación, Sevilla, 2005.

REGO, T. Vygotsky: uma Perspectiva Histórico-Cultural da Educação. 21. ed. Petrópolis, RJ: Vozes, 2010.

ROKEACH, M. Crenças, atitudes e valores. Rio de Janeiro: Interciência, 1981.

ROMANELLI, G.; BIASOLI-ALVES, Z. Diálogos Metodológicos sobre prática de pesquisa. Ribeiro Preto: Legis Summa, 1998.

SADALLA, A.M. Com a palavra a professora: suas crenças, suas ações. Campinas, SP: Alínea, 1998.

SCHOMMER-AIKINS, M. Explaning the Epistemological Belief System: introducing the embedeed systemic model and coordenated research. Educational Psychologist, v.39, n.1, p.19-29, 2004.

SHULMAN, L. Conhecimento e ensino: fundamentos para a nova reforma. Cadernos Cenpec, São Paulo, v.4, n.2, p.196-229, dez. 2014.

UHMANN, R.; ZANON, L. Pressupostos que marcam o ensino: examinar ou avaliar? In: HERMEL, E.; GÜLLICH, R.; GIOVELI, I. Ciclos de pesquisa: Ciências e Matemática em investigação. Chapecó, Ed. UFFS, 2016, p. 245-268.

VIGOTSKI, L.S. A construção do pensamento e da linguagem. Tradução de Paulo Bezerra. São Paulo: Martins Fontes, 2001. 